\title{
"Train your mind for a healthy life". The medicalization of mediatized mindfulness in the West
}

\author{
Marta Kołodziejska ${ }^{1}$ (i) $\cdot$ Michał Paliński $^{2}$
}

Accepted: 27 January 2022

(c) The Author(s) 2022

\begin{abstract}
The study analyses how the functions and purposes of mindfulness meditation practices are constructed in the narratives of the Headspace mobile application. The quantitative component deployed a semi-automatic, computer assisted text analysis of 964 posts on the Headspace blog, and involved topic modelling and keyword co-occurrence analysis. This step identified dominant topics within the sample, and key term associations, which informed the in-depth qualitative text analysis of the recordings of four Headspace meditation packs, and 45 blog posts written between 2014 and 2018. The analysis focused on identifying the narratives, defined as structured storylines with plots, actors, and attached meanings. The analysis has shown that in the Headspace narratives, the function and purpose of mindfulness is constructed with reference to science and medicine, which also positions the app and the services it offers among scientific achievements, rather than spirituality or alt-med movements. The medical authoritative framework manifests itself in links to research, and referring to problems and solutions in medical or therapeutic terms. Apart from the medicalization of the practice, its healthicization is also manifested in the repetitive encouragement to monitor one's health and actively improve one's wellbeing. In effect, the narratives associate taking care of one's health with the morally desirable behavior. The study concludes that the medicalization and healthicization of mindfulness identified in the app narratives shift the meaning and function of the practice from spiritual growth and enlightenment to a "will to health" and the obligation of constant self-monitoring.
\end{abstract}

Keywords Mindfulness applications $\cdot$ Medicalization $\cdot$ Healthicization $\cdot$ Mediatization

Ever since Mindfulness-Based Interventions (MBI), especially Mindfulness-Based Stress Reduction (MBSR) have gained popularity among the general public, the secularized, therapeutic interpretation of mindfulness has been the object of debates among Buddhist and non-Buddhist scholars and practitioners. One of the main focal points of these discussions has been the appropriation and possible distortions of Buddhist ethics and principles (Monteiro et al., 2015; Purser, 2019; Williams \& Kabat-Zinn, 2011; Wilson, 2014), as well as on the secularization of the spiritual practice for commercial purposes (Purser, 2019). From a critical viewpoint, Jeff Wilson argues that mindfulness has become the "basic part of the spiritual landscape of North America; authorized

Marta Kołodziejska

kolodziejskam@is.uw.edu.pl

1 Faculty of Sociology, University of Warsaw, U1. Karowa 18, 00-927 Warsaw, Poland

2 Digital Economy Lab, University of Warsaw, ul. Dobra 56/66, 00-312, Warsaw, Poland by science, endorsed by Oprah, marketed by Buddhists, appropriated by self-help gurus" (Wilson, 2014, p. 40). In the same vein, Ronald Purser and David Loy describe the ${ }^{1}$ popularity of the practice in the West as "McMindfulness" (Purser \& Loy, 2013), pointing to the fact that it has not only lost its original spiritual context and meaning, becoming an exercise encouraging individualization, and self-centeredness, but has also been used by large corporations as a powerful tool to turn employees into docile, compliant workforce (Purser, 2018, 2019).

The discussions encompass several ethical, spiritual, and practical dimensions of mindfulness, but in doing so, they are focused predominantly on the MBI-related programmes and self-help books, without paying sufficient attention to a growing domain of mediatized mindfulness, i.e. practices which take place with the use of media, or are available

\footnotetext{
${ }_{1}$ Throughout this paper, mindfulness will be defined as "the awareness that arises through paying attention in a particular way: on purpose, in the present moment, and nonjudgmentally" (Kabat-Zinn, 1994, p. 4).
} 
entirely through the media, such as mobile applications. In consequence, few of these works consider the media, and digital media in particular, important agents of the evolution of secularized mindfulness (cf. Borup, 2016a; Wilson, 2014). However, since in the last decade mindfulness meditation apps have become a flourishing market, worth over 1,2 million dollars and with millions of users worldwide, they should by all means be included in the debates. In 2019, two such apps were among the top five health and wellness mobile applications: Calm (50 million downloads, as of July 2019, see: Press, n.d.), and Headspace (approx. 65 million users across 190 countries, available also in German and French since 2019) (Headspace Fact Sheet, 2020). Thus far, several studies were conducted on how using the apps may affect the users' wellbeing, cognitive function, depression, and stress levels (Chittaro \& Vianello, 2016; Bennike et al. 2017; Economides et al., 2018; Strauss et al., 2021), but they have not been the object of a systematic sociological inquiry.

While this paper acknowledges the importance of the ethical debates and critiques, instead of engaging in them, it aims to advance the discussions further by including a sociological perspective on the mediatized mindfulness. As such, the goal of the paper is to answer the question of how in the app narratives (i.e. organized and connected storylines, actors, patterns of meaning, and common themes, cf. Keller, 2013, p. 124) the meanings, purposes, and functions of the practice are constructed. The basic premise is that since the app design and features differ from MBSR programmes or self-help books deploying mindfulness, it can be expected that the app content will also be different, and as such should not be viewed as yet another means of delivery of the same message, but as a distinctive message altogether. Considering that there are thousands of other meditation apps (Buddhist and secular alike), many of which were created long before their more successful competition, the popularity of these particular applications may indicate that the secularized mindfulness narratives they offer are especially appealing to consumers in the West. Hence, it can be assumed that the increased popularity of Headspace and Calm may translate into the emergence of new meanings, functions, and purposes of practicing mindfulness in the West, in light of which the analysis we propose aims to shed some light on how these meanings and functions are constructed. On the basis of a mixed-method analysis of the Headspace mindfulness app and blog posts, it will be argued that one of the contexts of the transformation of mindfulness through the app is its medicalization and healthicization. As a result, the primary meaning and function of the practice is shifted from spiritual growth and enlightenment to a "will to health" and the obligation of constant self-monitoring.

\section{The Mediatization of Mindfulness}

Mediatization is a term which captures "on the one hand the increasing spread of technologically based media in society; and on the other hand how different social domains are being more and more shaped by these media" (Hepp \& Hasebrink, 2018, p. 16). This concept considers the media as agents of change of communication and by that also the social construction of reality (Hepp \& Hasebrink, 2018, p. 16). Mediatization is not just about increased presence of media in society (more devices, more connections, etc.), but views media and media use as inherent in all human (and human-machine) communication. Intensive digitalization and the concurrent datafication had not only advanced the spread and reach of media, but also transformed the social world in a way that it "very deeply relies on these technologically based communication media", hence the term "deep mediatization" to describe the digital media environment (Hepp, Breiter, and Hasebrink 2018, p. 6). In times of deep mediatization, "the very elements and building blocks from which a sense of the social is constructed become themselves based on technologically based processes of mediation" (Hepp, Breiter, and Hasebrink 2018, p. 6). From this perspective, mindfulness is not only communicated, practiced, and experienced with the use of media, but also constructed, reinterpreted and reformulated in the process. A mobile app used for practicing mindfulness constructs a certain image or a representation of the practice, which is a combination of the creators' vision, marketing and promotional strategies, expected target audience, etc. An app for Buddhist meditation may offer a wholly different narrative on the purpose and meaning of mindfulness than a secular app intended for stress management.

The Headspace app (https://www.headspace.com/), created in 2010 by Andy Puddicombe and Richard Pierson, is a library of individual meditation sessions ("Singles"), and "Packs" consisting of ten to 30 sessions, each lasting on average between three and 20 min-the user chooses the desired session length. Typically, a brief introduction and summary discuss a topic of each session and theme, while the middle section comprises a set of standardized breathing exercises and guided meditations. Installation and access to an introductory meditation pack is free, but there is a fee for monthly subscription with unlimited access to all available packs and features. The packs are divided thematically: Health, Happiness, Brave, Work and Performance, and Sport are among the featured themes. The app is available in a desktop and mobile version, and has a colorful, cartoonish design, with characters such as a smiling or meditating brain appearing throughout the sessions. It 
also includes instructional videos on various meditating techniques, such as visualization. Headspace is intended for individual use, which is reflected in its structure, in which group-oriented features are limited to a group meditation session at a fixed time each day (the feature for paying subscribers was introduced in 2019, but participation is optional), and inviting friends to use the app. The focus on the individual is also reflected in the app's contents, since the guided meditation address one practitioner. The website hosted a lengthy blog (changed into Articles in 2021), ${ }^{2}$ with a couple of thousand posts on various topics, such as health, wellbeing, relationships, etc. Its scope went beyond explaining the features of the app and encouraging license purchase, and it is a lifestyle and wellbeing supplement to the app itself. Thus, both the app and the accompanying blog were chosen as the object of analysis. The popularity of Headspace reflected in the number of downloads and publicity, the fact that it advertises itself as part of science (and thus creates an association between mindfulness and the secular world, rather than religion or spirituality), and explicit marketing towards large corporations (the Press Kit mentions over 300 successful collaborations with multinational businesses such as Nike or Google) make Headspace a particularly adequate object of investigation. These factors, along with the app's features and content convey a certain representation of secularized mindfulness practices, their context, meaning, and function, which will hopefully offer a better understanding of the contexts of mindfulness practices in the West.

\section{The Medicalization of Mindfulness}

Medicalization is "a process by which nonmedical problems become defined and treated as medical problems, usually in terms of illnesses or disorders" (Conrad, 1992 p. 209). It entails a deployment of "a medical framework to understand a problem, or [uses] a medical intervention to "treat" it" (Conrad, 1992, p. 211). On a conceptual level, this process occurs when a medical vocabulary is used to define a problem, its causes and solutions, but medical interventions or treatments do not necessarily take place. This investigation of Headspace focuses specifically on the conceptual level, as it analyses how the narratives produced by the app are associated with medical terminology. Another level of medicalization, the institutional, in which "organizations may

\footnotetext{
2 As of July 2021, the blog exists under Articles (https://www.heads pace.com/articles). The former blog posts are changed into articles (without author names). The links to the blog quoted in the References are therefore redirected to the Articles' section. Their content remains unchanged.
}

adopt a medical approach to treating a particular problem in which the organization specializes" (Conrad, 1992, p. 211), pertains for instance to the efforts made by the Headspace app creators to obtain FDA approval as "prescription app" and a form of medical treatment. ${ }^{3}$

Medicalization is not necessarily associated with rationalization (Bull, 1990), but with providing a single authoritative framework, and ascribing authority to medical professionals and/or research. Conrad differentiates between medicalization and healthicization, associating the latter with contemporary wellness practices. Healthicization is health promotion which "proposes behavioral or lifestyle changes for previously biomedically defined events (e.g. heart disease)" and "turns health into the moral" (Conrad, 1994, p. 397). Healthicization reframes health and wellness as one's capital, and formulates taking care of one's mental and physical health as an individual responsibility and a moral obligation.

Although Conrad presents medicalization and healthicization as an opposition, it will be argued that the Headspace app encompasses both phenomena, depending on what facets of the app narratives are taken into consideration. Mindfulness practice is presented as part of scientific and medical achievement, which can be used to help solve certain health problems, manage symptoms and health conditions (including stress, anxiety, insomnia, burnout). As such, the effects of mindfulness are described in medical terms, with references to the authority of research and medical professionals, which pertains to the medicalization of mindfulness. Healthicization manifests itself in the narratives which suggest that addressing one's (mental and physical) health problems and symptoms, and following advice to become healthier and happier is an obligation, as the individuals should monitor their wellbeing, strive to improve it, and promptly address problematic issues.

It should be noted that following the definition above, to some extent MBSR may already be viewed as a medicalized practice: in particular when it involves the clinical setting, medical vocabulary used as a frame of reference and authority (naming health conditions and framing mindfulness practices as a form of supportive therapy), and affiliation with acknowledged medical institutions. Furthermore, MBSR, and other MBIs have been assessed in numerous studies, where the efficacy of the interventions was measured using scientific methods (Davidson et al., 2003; Baer et al., 2006; Hodgings and Adair 2010; Baer, 2011; Keng et al., 2011; Laurie and Blandford, 2016; Economides et al., 2018). These studies argue that regular meditation may have positive impact on cognitive functions, along with several other

\footnotetext{
3 http://blog.petrieflom.law.harvard.edu/2018/07/16/meditationtheres-an-almost-fda-approved-app-for-that/
} 
health benefits, which indicates that mindfulness programs have "objective" effects. Some authors emphasize that mindfulness is closely connected to medicine and science, which justifies and contextualizes the practice in secular societies (Wilson, 2014). Headspace, as an app which draws on the principles of MBIs, may be expected to undergo similar processes of medicalization: a comparison of these two forms of practice focused on the issue of medicalization would require a separate study. Simultaneously, Headspace is not an MBI-type program done online: the app's design, features, and focus make it a unique phenomenon, which produces a narrative of mindfulness with distinct features, which are the object of investigation in this paper.

\section{Method}

\section{Text Mining and Co-occurrence Analysis}

The quantitative analysis conducted was based on the text data webscraped from the Headspace blog (www.headspace. com/blog): 964 posts were used in the analysis. For the purpose of the study, a semi-automatic computer-assisted text analysis was deployed, using a standard topic modeling technique and keyword cooccurrence identification. All posts were webscraped in August 2018.

Topic modeling enabled the identification of the main themes present in the blog corpus without any assumptions about the relevant keywords appearing in the texts. Topic modeling refers to a combination of "algorithms for discovering the main themes that pervade a large and otherwise unstructured collection of documents" which "can organize the collection according to the discovered themes" (Blei, 2012a, p. 77). The most popular method of topic assignment is the Latent Dirichlet Allocation (LDA) model (Blei et al., 2003), which is a probabilistic topic model using Bayesian formulation to reveal hidden (latent) topics in the given text corpus. ${ }^{4}$ Topics obtained via LDA analysis are probability distributions over terms (Blei, 2012b). This study deployed an LDA model while setting the number of topics on the basis of stability analysis using the top-weighted Jaccard index (Ignatow, \& Mihalcea, 2017). The LDA analysis was conducted in Python using Gensim 3.5 package. Standard text preprocessing consisting of four steps-removing stopwords, conversion to lowercase, tokenization, and vectorization- was conducted using the Sci-kit learn machine learning package. As a result, over 20 topics were retrieved from the Headspace blog corpus - identified with ordinal

\footnotetext{
${ }^{4}$ Being an unsupervised machine learning algorithm, LDA does not require providing a training dataset nor manual coding of the document.
}

numbers. Due to limited space, this paper discusses five of them (Table 1).

In order to deepen the quantitative analysis, for the purpose of this paper co-occurrence analysis of four keywords was performed, and consisted of two major steps. Firstly, four keywords (body, suffering, mind, and community) were chosen: they were selected from the list of terms within the 20 identified topics. The selection was purposeful, and its aim was to choose keywords pertaining to the aspects of human life that may be improved by meditation and that also appear in the app recordings. Suffering was chosen as a keyword which is connected with the Buddhist concept of dukkha adapted by MBSR (see above), to investigate what phrases co-occur with it and what domain they pertain to (spirituality, medicine, psychology, etc.). Two keywords were found repeatedly in several topics (body, mind), and two appeared rarely (suffering, community). Secondly, the words frequently mentioned with the four keywords were identified. This was achieved by dividing the number of texts containing both terms (pre-identified keyword and a potential keyword) by the number of texts including preidentified keywords of interest. As a result, four ranked lists of co-occurring terms were obtained and will be presented below (Fig. 2).

\section{Qualitative analysis of the Headspace sessions and blog posts}

To build on the quantitative study, the qualitative module consisted of two data corpora: 1) the recordings of four selected

Table 1 Selected topics identified in the Headspace blog corpus. Source: own elaboration

\begin{tabular}{|c|c|c|c|}
\hline $\begin{array}{l}\text { Topic 1: } \\
\text { thoughts } \\
\text { anxiety } \\
\text { feelings } \\
\text { person } \\
\text { self } \\
\text { experience } \\
\text { meditation } \\
\text { moment } \\
\text { practice } \\
\text { relationship }\end{array}$ & $\begin{array}{l}\text { Topic 2: } \\
\text { brain } \\
\text { stress } \\
\text { mindfulness } \\
\text { self } \\
\text { meditation } \\
\text { health } \\
\text { research } \\
\text { researchers } \\
\text { depression } \\
\text { studies }\end{array}$ & & $\begin{array}{l}\text { Topic 3: } \\
\text { social } \\
\text { media } \\
\text { phone } \\
\text { online } \\
\text { friends } \\
\text { technology } \\
\text { facebook } \\
\text { relationship } \\
\text { dating } \\
\text { attention }\end{array}$ \\
\hline $\begin{array}{l}\text { Topic 4: } \\
\text { food } \\
\text { eating } \\
\text { mindful } \\
\text { diet } \\
\text { weight } \\
\text { body } \\
\text { habits } \\
\text { choices } \\
\text { guilt } \\
\text { obesity }\end{array}$ & & $\begin{array}{l}\text { Topic 5: } \\
\text { sleep } \\
\text { pain } \\
\text { insomnia } \\
\text { chronic } \\
\text { bedtime } \\
\text { caffeine } \\
\text { management } \\
\text { depression } \\
\text { treatment } \\
\text { effects }\end{array}$ & \\
\hline
\end{tabular}


Headspace meditation packs: Basics (30 sessions), Relationships (30 sessions, part of the Happiness theme), Productivity (10 sessions, part of the Work and Performance theme), and Coping with Cancer (30 sessions, part of the Health theme), and 2) 45 Headspace blog posts written between 2014 and 2018. All recordings were downloaded between January and April 2018, and screenshots from the sessions (desktop app version) were used as an additional data source. The license for app use was purchased by one of the authors. The Headspace blog posts were selected based on a two-stage sampling process. Twenty posts in total (i.e. five posts per category) were taken from the "Work", "Living", "Death" and "Health" post categories, as those were most relevant to the themes of the study. The remaining 25 posts were sampled from all articles containing predefined short lists of keywords listed below:

1. 'insight', 'comprehension', 'contemplation', 'realization'

2. 'health', 'sickness', 'anxiety', 'wellbeing'

3. 'community', 'relationship', 'colleague', 'community'

4. 'individual', 'personal', 'myself', 'emotions'

5. 'productivity', 'boost', 'results'.

In order to be selected, the blog post had to contain at least one of the predefined keywords. As in the former sampling approach, five posts were taken from each list. The keyword selection took into account the frequency of words in the blog corpus. The most frequently appearing and generic words have been avoided for the sake of achieving a thematic differentiation of the selected posts. In order to assure reproducibility, in both cases the selection was performed using the pseudo-random number generator.

The collected blog and app recording material was then analyzed following the principles of the Sociology of Knowledge Approach to Discourse (SKAD). This approach was chosen as particularly relevant, as it focuses on the processes of knowledge production, in a three-step analytical procedure whose objective is to reveal the phenomenal structure, meaning patterns, and narrative structures which organize the "content of an utterance" (Keller, 2013, p. 113). SKAD is therefore interested in how meanings, values and knowledge are constructed, disseminated, and interpreted. In the case of the Headspace content, the key research question was how the meaning, function, and purpose of mindfulness practices is constructed in the app, and what the typical narratives encompassing these aspects of mindfulness are.

\section{Results}

\section{Health as One of Key Topics}

The thematic categorization of Headspace blog posts has shown that "Living", "Health", and "Meditation" are the most densely populated categories constituting almost $90 \%$ of texts in the Headspace blog corpus, and that the highest number of posts was published in 2017 (Fig. 1).

These results are hardly surprising, given the promotional strategy of the Headspace company, and its focus on health and well-being. Topic identification (Table 1) has further emphasized the connection between the Headspace narratives and health:

Table 1 above presents five topics identified using LDA within the Headspace blog..$^{5}$ Overall, among 50 keywords, 23 pertain to medicine, health, and science. Those keywords can be grouped into health and medical conditions (obesity, anxiety, [chronic] depression, stress, insomnia), symptoms (pain), forms of treatment and managing symptoms or issues (management, diet, treatment), body parts and parameters (body, brain, weight), things affecting the body (caffeine, food, eating), and terms connected to research (researchers, studies).

This basic inquiry points to a connection between the conceptualization of mindfulness and health and medicine in the Headspace blog posts. It may be inferred that the app focuses on various ailments, health problems and risks, and includes scientific research as an important reference point. Furthermore, as Fig. 2 below illustrates, almost all terms co-occurring with the keywords "body", "mind", and "suffering" can be associated with medicine and science. The body is represented through its elements (hormones, muscles, pounds [weight]), and functions or processes, which may need to be addressed.

Similar terms are related to "mind": "evidence-based", "peer-to-peer", and "effectiveness" reveal a connection with research, evaluation, and reliability. Terms such as "racing", and "wandered", while not pertaining to medicine and research per se, are indicative of relations with mental health and wellbeing. A "racing mind", like ruminating, is a common issue that meditation is said to help address, by enabling the individual to retain focus and peace of mind. The third keyword, "suffering", is also strongly associated with medical terms, such as "stressors", "medication", "reduces", "treating", "neural", and "reduction", which indicate that Headspace generally associates suffering with stress. The emotional aspect of suffering appears only through the keyword, "ashamed", but its spiritual connotations are omitted. This reduction of suffering to stress-related issues is particularly interesting when compared to the MBSR's broad understanding of suffering, which is closer to the Buddhist concept of dukkha. A departure of this kind may be indicative of a change of a framework of reference, i.e. from one

\footnotetext{
5 The list is the effect of a combination of automated LDA identification of the most prevalent (frequent) topics and a manual selection of the most illustrative ones. The most distinctive terms were chosen, excluding stopwords and generic words.
} 


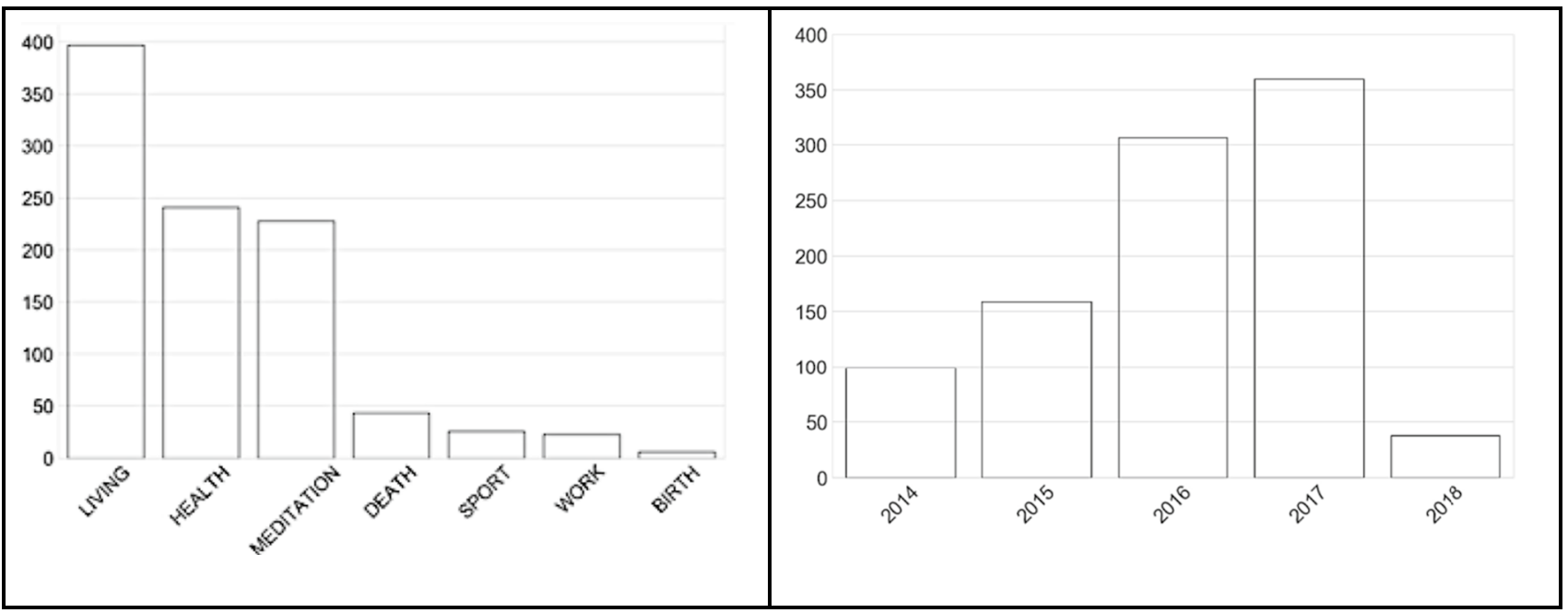

Fig. 1 Headspace blog posts grouped by category (left) and year (right). Source: own elaboration

which combines ethical, spiritual, therapeutic and medical dimensions to one which focuses on the medical, physiologic frame of reference. Thus, it may be concluded that Headspace narratives define suffering in medical terms, as a problem which can be mitigated or solved with the help of meditation.

Interestingly, a similar medical association is not made with "community". The co-occurring terms pertain to its qualities ("spiritual", "isolated", "rewarding", "weird") instead of appealing to the health of the population, diseases, etc. This exception may be attributed to the app function itself: it is meant to be used by individuals, whose problems, medical conditions, and potentially harmful habits mindfulness meditation may help manage. Thus, the presence of others is important insofar as it is related to individual experiences and actions, or personal problems that need to be addressed-stress being the major one.

In numerous interviews and talks that Puddicombe has given since the launch of the app, he has emphasized the scientific approach to mindfulness the company embraces, showing that Headspace builds on the research on meditation, and develops it further in a unique way (Jilla, 2019; Widdicombe, 2015). Interestingly, while terms like "religion" and "spirituality" do not appear on the Headspace blog (Buddhism is only mentioned in two posts showcasing the career of Puddicombe, an ex-Buddhists monk), there are ample references to science and scientific expertise-mostly in relation to the efficacy of mindfulness meditation. This implicitly distances the creators of Headspace, the app itself, and in consequence also mindfulness practices from some of the wellness and alt-med trends which discourage people from seeking medical advice, or openly reject the achievements of modern science (cf. Brueck, 2018). This is also reflected in some of the statements found on the Headspace website:

At Headspace we see meditation as both a practice rooted in ancient history and a topic of modern science. This is why we are as equally committed to providing authentic expertise in meditation and also studying the science of meditation. Science has been an integral part of the Headspace business since day one. We recognize that the only way to know if we are achieving our goal of improving the health and happiness of the world is to measure it. That's where the research comes in. There are over 2,000 meditation apps out there, but Headspace is one of the only ones committed to advancing the field of mindfulness meditation through clinically-validated research on our product. We are currently in progress on research studies with large national institutions that could be among the largest mindfulness meditation trials ever conducted (Scientific Rigor, n.d.).

\section{Medical Framework of Stress Reduction}

The connections between mindfulness practice, health and medicine which are highlighted by the quantitative analysis manifest themselves vividly in the blog posts, especially those devoted to stress. Managing stress is presented not so much as a form of regulating one's mood as taking care of one's mental and physical health. Mindfulness meditation, in the form of the Headspace sessions, is offered as a means to this end. In the app, stress is addressed as an unpleasant emotion and experience, which can be acknowledged, dealt with, and eventually let go. Simultaneously, the Headspace narratives explain the 
Fig. 2 Co-occurrence analysis of the terms present in the Headspace blog corpus. Source: own elaboration

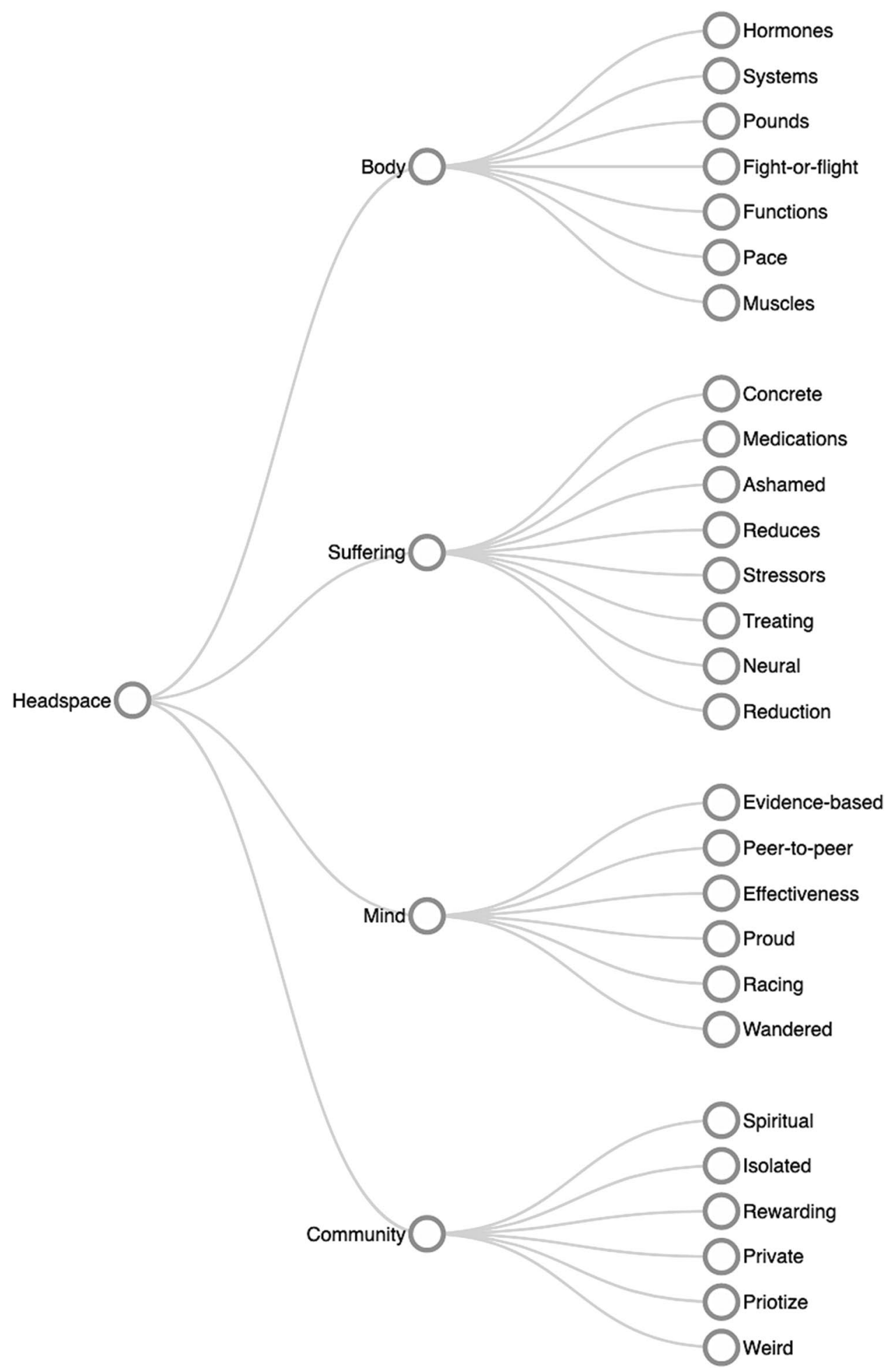

physiological processes behind stress and stress reduction, with the use of medical terminology and references to medical authority:

"What we've found is that if you stimulate pressure receptors deep under the skin, there's a long chain reaction," says Field. This cascade stimulates the vagus nerve, a key member of the parasympathetic nervous system, which tells your body to relax. Not only does your breathing slow, but your heart rate, blood pressure, and stress hormone levels drop. Field says they've also found increased levels of serotonin 
as well as the immune system's natural killer cells (Yu, 2017).

In the excerpt above, a researcher is quoted, giving a detailed, research-based account of physiological reactions to touching. This excerpt may help the reader understand the mechanisms and processes behind stress, but it also frames the latter as a problem which can be measured and investigated, that has concrete causes and effects, and as such, one that can be effectively solved with the help of medicine.

Stress is also discussed as an issue which can become a burden or an obstacle to happiness and self-acceptance:

Imperfections, flaws, foibles, and mistakes can cause great stress and anxiety in people with lower selfacceptance. Studies also show that diminished selfacceptance can threaten our psychological well-being (...). Without self-acceptance, we may get stuck in negative thought patterns which can contribute to mental and physical illness. Research shows that the very strategies we rely on to manage adversity - like mindfulness and gratitude - become more difficult to practice when self-acceptance is deficient (Campbell, 2017).

Stress is represented as a complex matrix of psychological and physiological factors, symptoms, and effects, but also as a risk: giving in to stress decreases self-acceptance, which may contribute to illnesses. Here, again research is referred to in support of the author's claim, but the overall narrative of the post is not simply informative or explanatory, but argumentative. The author gives advice to nurture self-acceptance and gratitude, along with some tips on how to practice them, as they are important features of well-being and have a concrete impact on one's health.

Both examples above point to a medical authoritative framework: medical terminology and references to research are used to justify claims, provide contexts, emphasize reliability and transparency of what mindfulness meditation can offer. In this sense, the traditional religious authority of monks, sacred texts, and religious community (cf. Campbell, 2007) is replaced with the community of health professionals.

In another persuasive post, guilt is presented as a psychological and physical issue which influences how we act, and has several observable, health- and wellbeing related consequences (like binge-eating, being unsuccessful). The text explains some positive functions of guilt, and offers advice on how to cope with this emotion, simultaneously warning against using guilt as motivation:

"Guilt doesn't solve problems, it amplifies them," says Chris Hodges, who runs GoTRIBE Fitness. The L.A.based trainer says guilt puts an unnatural stress on the human body and can actually cause people to turn to vices like junk food as a coping mechanism. (...) Don't use guilt as a driver for success, use grace and persistence," Hodges explains. "You have a way better chance of succeeding" (Pajer, 2016).

The last two excerpts discussed above show that stress and stress-related problems are presented as obstacles to health and wellbeing. The blog encourages its readers to find solutions to overcome them, and offers professional advice and tips on how to manage stress. By not addressing these problems, the reader jeopardizes her health and wellbeing, and puts herself at risk of illness and unhappiness. This indicates that not only a medical authoritative framework is imposed, but also an ethical or moral imperative is ascribed to managing stress and stress-related problems. The texts clearly define what is positive and negative, and suggest a desirable course of action to prevent the negative from dominating one's life.

\section{The Imperative of Wellbeing}

In comparison with the Headspace blog, the app meditation sessions include fewer references to science or medicine in the context of taking care of one's health and wellbeing. Those references can be identified mostly in the repetitive reminders that the mind can be "trained for a happier, healthier life" (Basics). Other meaningful references to science and research include:

"(...) meditation may have already changed your brain" (Basics 1, screenshot*6).

"There is a direct correlation between how we look after our bodies and how productive we are" (Productivity, session 8).

"We're creating a framework in which we can observe the disorder of the mind" (Productivity, session 4).

The first statement encourages the users to meditate not only because it may positively affect their lives, but also because it may have a lasting, desirable effect on their brains. In fact, some studies have shown that meditation contributes to the creation of new neural pathways, which was also discussed by several media sources, including Forbes (Loder, 2015), Mindful.org (Willard, 2016), and Psychology Today (Bergland, 2016). Headspace makes a connection with these studies and suggests that meditating (also with the use of the app) offers a scientifically-proven enhancement (but not a medical treatment per se) of the mind and body.

The second quote above reminds the user that productivity can be improved by various means, and taking care of

\footnotetext{
${ }^{6}$ Statements marked with an asterisk were found in the app in 2018, but do not appear in the app version accessed in July 2019 and later. All app quotes refer to the version available in 2018.
} 
the body is one of them. It also indirectly suggests that the purpose of practicing mindfulness is linked to taking care of oneself, in a similar vein to exercising or eating a balanced diet, and will allow anyone to "get far more out of life" (Relationships, session 10). This connection appears throughout multiple sessions, which further reassures the user that all areas of her life can be potentially improved with the help of mindfulness. It also implicitly suggests that a healthy, happy life can be achieved through an individual, informed effort.

The last quote cited above includes the phrase "disorder of the mind", which may be interpreted as a lack of order (unstructured thoughts, wandering mind), but also as an abnormality, or a derangement of the function of the mind, a morbid mental state (disorder, n.d.). The implicit suggestion, and a normative statement, is that human minds are disordered "by nature", and that effort must be made to restore the order and redress the balance. Mindfulness is an instrument of such restoration, not so much through rigor and control, but observation and structured, systematic action (like regular meditation). Furthermore, the app narratives suggest a number of solutions and ideas for health improvement, and show that they are in fact within everyone's reach. Consider the quotes below:

Thoughts can be enjoyable, but if we let the mind wander whenever it wants, we miss opportunities to be mindful (Basics 2, session 9).

Each day is a new opportunity to practice mindfulness and feel happier and healthier (Basics 1, session 10). Perhaps we don't get to choose how sensitive we are, or what we are sensitive to, but we do have a degree of control over how skillfully we respond to those feelings. It's in this particular area that the practice of mindfulness is so useful. And (maybe you saw this one coming) another reason to download the Headspace app, and start meditating today (Headspace, 2014).

Take an honest look at what you eat, when you eat, and how it makes you feel. Are you eating foods that are conducive to being productive? (Productivity, session 9).

The aforementioned excerpts include various forms of persuasion: highlighting the applicability and usefulness of Headspace, its positive function in managing emotions and productivity, offering advice and suggestions, as well as (explicitly and implicitly) suggesting the possible consequences of not following the guidelines. One of the underlying notions that the segments have in common is that of improvement opportunities which should not be missed - a recurring theme in the Headspace narratives (see below). The individual is presented as an adjudicator of her mental or physical disorders, in the process of making a positive change. There are no definitions on what living happily and healthily means, but the app narratives propose several fillings of these terms, such as focusing on the positive aspect of things, following a balanced diet and exercise routine, being productive, emotionally stable, extraverted, agreeable, as well as being conscientious (organized, hard-working, responsible), and open-minded (cf. Quandt, 2018). Furthermore, it is often implied that one should strive to acquire those positive qualities and undertake the recommended actions in order to be happy and healthy:

"Personality traits are linked to a wide array of incredibly important life outcomes, including occupational success, relationship satisfaction, and even health and mortality," said Hudson. He said the research suggests we don't have to wait for a life change to passively affect our personalities. Instead, "people may be able to take a more active role in shaping their own personality traits, as well" (Quandt, 2018).

The good news is that the choices we make can help us avoid this path. "The best thing people can do is choose what they expose themselves to more carefully and consciously" (Breslouer, 2017).

The old "if I ignore it, it will eventually go away" argument just does not fly when it comes to a persistent stressor. We are fooling ourselves if we believe our circumstances will magically improve without recognition of the problem and a plan of action to address it (Medlock, 2017).

Taking a passive role in changing one's personality or waiting until a problem "solves itself" means that one risks being unsuccessful, unhappy, and unhealthy, at least as far as mental health is concerned. Emphasizing the availability of the proposed solutions may suggest that not reaching for them is a form of negligence. These statements make the reader cognizant of the need to monitor one's health and wellbeing, to identify and actively manage any problems and shortcomings. While it is advised to reach out for professional help (therapists, dietitians, etc.) when necessary, the responsibility of self-monitoring, and self-amendment is bestowed upon the individual. It is also suggested in the Headspace narratives that how one feels may have an effect on other people, so taking care of oneself is not just an obligation towards oneself, but also towards others: family members, friends, or coworkers. The excerpts below include such overt reminders:

And while you can't "catch" clinical depression from a friend, some symptoms of depression-helplessness, tiredness, and loss of interest—can spread, which could have implications for identifying subclinical levels of depression. "The effect from your worse mood friends is usually not strong enough to push you over the line into clinical depression," says Eyre (Yu, 2017). 
Meditation doesn't just affect you. It affects everyone around you too. We're making friends with our own mind. And that helps us make friends with those around us. Meditation can change a lot when you realize how it impacts yourself and also those around you (Basics 2, session 1).

Why are you here today? Who else might benefit from you doing this exercise? (Basics 2, session 2).

By taking an active role in managing one's health and wellbeing, one shows conscientiousness and responsibility, but also consideration for other people. From another perspective, all the aforementioned excerpts imply that in most cases, there is room for improvement and the possibility for the individual to become healthier and happier. The app promotes a proactive attitude and a positive outlook, and frames some health conditions and illnesses as "challenges" or "challenging journeys" (as in the Coping with Cancer pack), i.e. competitive situations, a call out to combat or confrontation. Hardships and tribulations are acknowledged and presented as a normal, natural part of life, but simultaneously the narratives of the app advocate for approaching them with a positive, focused mindset.

\section{Conclusion}

This paper aimed to contribute to the discussion of how the affordances of digital media, such as mobile apps, may affect the forms and meanings of mindfulness practices in the West. It was argued that the Headspace app narratives transform the meaning and function of mindfulness meditation, shifting it further into the realm of science and medicine, and contributing to the medicalization and healthicization of the practice.

The functions and structure of the app itself play an important role in the transformation of meditation, in that they determine how and to what end mindfulness can be practiced. Headspace is intended for individual use, and there are few overt incentives to practice with a group, so the individual interacts with the application and the device. The app acts as an intermediary between the individual, the narrator, and the scientific authority, and its design structures and directs the interaction. Information and advice is transmitted from the app to the user, which also affirms the roles of producer and recipient. Ascribing authority to medicine and science, also by sharing links to research for validation and support of the claims (without quoting sources which are more cautious or skeptical about the health benefits of mindfulness meditation) constructs a very uniform representation of the purpose and function of mindfulness meditation.

In terms of content, the app produces a complete and coherent image of mindfulness practices. One does not have to have any prior knowledge on Buddhism, or meditation in general (a statement which is repeated in the Basics pack, for instance) in order to practice with the app and attain the desired goals. The blog does not discuss other, religious or secular, approaches to mindfulness, and instead enables the reader to become familiar with current research on the beneficial effects of meditation. In the narratives, as was mentioned above, every issue is analyzed from the practitioner's perspective, and relationships are also discussed from the viewpoint of how one participates in them and to what effects.

In the app recordings and blog posts, medicalization manifests itself in numerous references to medical and scientific authority, research findings, etc. The body, suffering, and the mind co-occur with terms pertaining to body parts, physiological processes, symptoms, and forms of treatment. While the ailments and symptoms are usually already medicalized conditions (stress, depression, burnout, etc.), the use of mindfulness becomes part of a medicallygrounded, scientifically-proven intervention. Meditation as a non-medical practice is presented as part of scientific achievement through studies on its efficacy, measurable health benefits, and recommendations from health specialists. Medical authority is referred to extensively in the blog posts to support the claims made by the app, enhance their credibility and put them in the medical/scientific context. In the app recordings, the narrator's voice guides the practitioner through the steps of each session, but the object of transmission is skill (as in gaining knowledge of the different types of exercise, being able to follow the guidelines, and eventually achieving effortlessness in immersing oneself in the practice) rather than wisdom. The narrator assumes the position of a guide and a teacher, but also-if we consider the blog as well-a representative of a scientific domain. The Headspace's request for FDA approval indicates that this connection is strengthened in a deliberate manner, shifting mindfulness meditation away from religion and spirituality towards science and medicine.

At the same time, the app narratives include numerous persuasive statements, which show that meditation canand should - be used to help oneself become happier and healthier. The app suggests where being happy and healthy stems from and how it is conducive to being productive, extravert, focused, and fit. To achieve happiness and health, one should embrace a proactive attitude towards oneself, i.e. one which involves monitoring one's physical and mental health, identifying problems and challenges, and making informed efforts to solve, mitigate, and manage them (and one of the functions of mindfulness meditation is precisely that). The need for self-monitoring and health management is not challenged by alternative opinions or sources within the app: all the supporting content affirms its validity and reasonability. And since one can only control what one does 
and how one reacts, the responsibility to do so also becomes individualized. As Alex Caring-Lobel put it: "If your most important manager is yourself, constraints become exclusively personal, the result of your personal dispositions, and the only thing holding you back from self-actualization" (Caring-Lobel, 2016, p. 208). Being passive and lacking the drive to improve oneself is shown as risky behavior, which may have several detrimental effects on the individual and the people around. Thus, the need to monitor one's health and wellbeing is presented as a moral and ethical obligation, rather than a choice one may or may not make. The "will to health" requires consistency (to ensure regular practice), and a certain degree of discipline (to follow the guidelines, make time for practice), but the app encourages the practitioner to start with a manageable goal, and advises beginners to "anchor the practice to another part of their daily routine" (Basics 1, session 4), so that mindfulness meditation becomes an everyday activity supporting mental hygiene.

The analyses of medicalization and healthicization of the practice dovetails with what Nikolas Rose wrote on the modern societies of control (cf. Foucault, 2003a, 2003b) and the "politics of life itself" (Rose, 2001, 2007). Nikolas Rose contends that control became ingrained in all aspects of our social existence, and so the individual is not so much the subject of disciplinary techniques, but has internalized both the obligation to monitor, evaluate, and modify her health and wellbeing, and the responsibility to act in response to the ever-changing conditions and requirements (2007, p. 223). Rose adds that.

our somatic, corporeal, neurochemical individuality now becomes a field of choice, prudence, and responsibility. It is opened up to experimentation and to contestation (Rose, 2007, p. 40).

This shift to self-management and monitoring can be partially attributed to the modern state relinquishing some of its health management responsibilities (cf. Lilja \& Vinthagen, 2014). Rose contends that as a result:

Organizations and communities are also urged to take an active role in securing the health and well-being of their employees and members. This new 'will to heath' is increasingly capitalized by enterprises ranging from the pharmaceutical companies to food retailers (...) (Rose, 2001, p. 6).

Mindfulness practices, offered by the app, may serve a similar purpose. The Headspace narratives on productivity, health and wellbeing appeal on the one hand to companies, offering help in taking care of employee mental health, and on the other hand to the individuals themselves, who feel obliged to monitor their health and wellbeing, and train themselves to acquire the desired qualities. Headspace provides its users with scientific reliability, a set of problem identifications, along with the possible solutions to the common ailments of today. In this context, mediatised mindfulness can be viewed as a form of internal training, or as an exercise belonging both to "selfoperation" and "having oneself operated on" (Sloterdijk, 2013, p. 374). In fact, mediatized mindfulness may be used to answer to the imperative "You must change your life" (Sloterdijk, 2013, p. 25; cf. Borup, 2006b, p. 12), which is the inherent part of the Western culture today.

Data availability The datasets from the blog content generated and analysed during the current study are available in the Authors' repository, at: https://drive.google.com/file/d/12CB_jt_ynUKXL6FgYUljn7 u4WlUuoYHr/view?usp=sharing.

Since some of the app content is not publicly available, the Authors have decided not to include the app data in the repository.

The paper does not include research involving human subjects, hence informed consent was not required. All analysed content was sourced from the blog (public) and app (free content and content available after subscription), following the right to quote and fair use principles. The analysis was conducted in conformity with sociological research ethics (cf. ISA Code of Conduct) and methodological standards. The authors confirm the paper is an original work, and declare no conflict of interests.

\section{Declarations}

Ethical statement The paper does not include research involving human subjects, hence informed consent was not required. All analysed content was sourced from the blog (public content) and app (free content and content available after subscription). The analysis was conducted in conformity with sociological research ethics (cf. ISA Code of Conduct) and methodological standards, following the right to quote and fair use principles. The authors confirm the paper is an original work, and declare no conflict of interests.

Open Access This article is licensed under a Creative Commons Attribution 4.0 International License, which permits use, sharing, adaptation, distribution and reproduction in any medium or format, as long as you give appropriate credit to the original author(s) and the source, provide a link to the Creative Commons licence, and indicate if changes were made. The images or other third party material in this article are included in the article's Creative Commons licence, unless indicated otherwise in a credit line to the material. If material is not included in the article's Creative Commons licence and your intended use is not permitted by statutory regulation or exceeds the permitted use, you will need to obtain permission directly from the copyright holder. To view a copy of this licence, visit http://creativecommons.org/licenses/by/4.0/.

\section{References}

Baer, R. A. (2011). Measuring mindfulness. Contemporary Buddhism, 12(1), 241-261. https://doi.org/10.1080/14639947.2011. 564842

Baer, R. A., Smith, G. T., Hopkins, J., Krietemeyer, J., \& Toney, L. (2006). Using Self-Report Assessment Methods to Explore Facets of Mindfulness. Assessment, 13(1), 27-45. https://doi. org/10.1177/1073191105283504 
Bergland, C. (2016, April 2). Mindfulness Training Optimizes Brain Connectivity. Psychology Today. https://www.psychologytoday. $\mathrm{com} / \mathrm{us} / \mathrm{blog} /$ the-athletes-way/201604/mindfulness-trainingoptimizes-brain-connectivity. Accessed 01 July 2021.

Blei, D. M. (2012a). Probabilistic topic models. Communications of the ACM, 55(4), 77-84. https://doi.org/10.1145/2133806. 2133826

Blei, D. M. (2012b). Topic Modeling and Digital Humanities. Journal of Digital Humanities, 2(1). http://journalofdigitalhuma nities.org/2-1/topic-modeling-and-digital-humanities-by-davidm-blei/. Accessed 01 July 2021.

Blei, D. M., Ng, A. Y., \& Jordan, M. I. (2003). Latent Dirichlet allocation. Journal of Machine Learning Research, 3, 993-1022.

Borup, J. (2016a). Branding Buddha - Mediatized and Commodified Buddhism as Cultural Narrative. Journal of Global Buddhism, $17,41-55$.

Borup, J. (2016b). Mindfulness as a booming, diverse and (non) religious phenomenona. Mapping and analyzing mindfulness in the city of Aarhus. Religion I Danmark, 7(2), 1-16.

Breslouer, L. (2017, May 28). We'll always be anxious. Here's what to know about it. The Headspace blog. https://www.headspace.com/ blog/2017/05/28/age-of-anxiety/. Accessed 02 July 2021.

Brinkerhoff, M. B., \& Jacob, J. C. (1999). Mindfulness and QuasiReligious Meaning Systems: An Empirical Exploration within the Context of Ecological Sustainability and Deep Ecology. Journal for the Scientific Study of Religion, 38(4), 524-542. https://doi. org/10.2307/1387610

Brueck, H. (2018, September 5). Gwyneth Paltrow's Goop must stop making bogus claims about its $\$ 66$ "vaginal eggs" because of a legal settlement. Business Insider. https://www.businessinsider. com/what-is-a-vaginal-egg-goop-lawsuit-2018-9?IR=T. Accessed 02 July 2021

Bull, M. (1990). Secularization and medicalization. The British Journal of Sociology, 41(2), 245-261.

Campbell, H. (2007). Who's got the power? Religious authority and the Internet. Journal of CMC, 12, 1043-1052. https://doi.org/10. 1111/j.1083-6101.2007.00362.x

Campbell, P. (2017, February 18). How to like yourself just a little bit more. The Headspace blog. https://www.headspace.com/blog/ 2017/02/18/how-to-like-yourself/. Accessed 02 July 2021.

Caring-Lobel, A. (2016). Corporate Mindfulness and the Pathologization of Workplace Stress. In R. E. Purser, D. Forbes, and A. Burke (Eds.), Handbook of Mindfulness: Culture, Context, and Social Engagement (pp. 195-214). Spriger International Publishing. https://doi.org/10.1007/978-3-319-44019-4_14.

Chittaro, L., \& Vianello, A. (2016). Evaluation of a mobile mindfulness app distributed through on-line stores: A 4-week study. International Journal of Human-Computer Studies, 86, 63-80. https:// doi.org/10.1016/j.ijhcs.2015.09.004

Conrad, P. (1992). Medicalization and Social Control. Annual Review of Sociology, 18, 209-232.

Conrad, P. (1994). Wellness as virtue: Morality and the pursuit of health. Culture, Medicine and Psychiatry, 18(3), 385-401. https:// doi.org/10.1007/BF01379232

Davidson, R. J., Kabat-Zinn, J., Schumacher, J., Rosenkranz, M., Muller, D., Santorelli, S. F., \& Sheridan, J. F. (2003). Alterations in Brain and Immune Function Produced by Mindfulness Meditation. Psychosomatic Medicine, 65(4), 564-570. https://doi.org/ 10.1097/01.PSY.0000077505.67574.E3

disorder. (n.d.) Miller-Keane Encyclopedia and Dictionary of Medicine, Nursing, and Allied Health, Seventh Edition. (2003). Accessed 09 July 2021 from https://medical-dictionary.thefreedictionary.com/disorder

Economides, M., Martman, J., Bell, M. J., \& Sanderson, B. (2018). Improvements in Stress, Affect, and Irritability Following Brief Use of a Mindfulness-based Smartphone App: A Randomized
Controlled Trial. Mindfulness, 9(5), 1584-1593. https://doi.org/ 10.1007/s12671-018-0905-4

Foucault, M. (2003). Discipline and Punish. The Birth of the Prison (A. Sheridan, Trans.). New York: Vintage Books.

Foucault, M. (2003). Society Must Be Defended: Lectures at the Collège de France, 1975-1976 (D. Macey, Trans.). New York: Picador.

Headspace. (2014, November 18). Is sensitivity an excuse for bad behavior? The Headspace blog. https://www.headspace.com/ blog/2014/11/18/what-kind-of-sensitive-are-you/. Accessed 02 July 2021.

Headspace Fact Sheet (2020, January). Headspace.com. https://www. headspace.com/press-and-media. Accessed 02 July 2021.

Hepp, A., Breiter, A., and Hasebrink, U. (2018). Rethinking Transforming Communications: An Introduction. In A. Hepp, A. Breiter, and U. Hasebrink (Eds.), Communicative Figurations: Transforming Communications in Times of Deep Mediatization (pp. 3-13). Palgrave Macmillan. https://doi.org/10.1007/ 978-3-319-65584-0_1.

Hepp, A., and Hasebrink, U. (2018). Researching Transforming Communications in Times of Deep Mediatization: A Figurational Approach. In U. Hasebrink, A. Hepp, and A. Breiter, Communicative Figurations. Transforming Communications in Times of Deep Mediatization (pp. 15-48). Palgrave Macmillan. https://doi.org/10.1007/978-3-319-65584-0_1.

Ignatow, G., \& Mihalcea, R. F. (2017). Text Mining: A Guidebook for the Social Sciences. Sage.

Jilla, S. (2019, March 7). Andy Puddicombe on bringing mindfulness to medicine. $G Q$. https://www.gq-magazine.co.uk/article/ andy-puddicombe-meditation-interview. Accessed 02 July 2021.

Kabat-Zinn, J. (1994). Wherever you go, there you are: Mindfulness meditation in everyday life. Piatkus.

Keller, R. (2013). Doing discourse research. An introduction for social scientists (B. Jenner, Trans.). London: Sage.

Keng, S.-L., Smoski, M. J., \& Robins, C. J. (2011). Effects of mindfulness on psychological health: A review of empirical studies. Clinical Psychology Review, 31(6), 1041-1056. https://doi.org/ 10.1016/j.cpr.2011.04.006

Krotz, F. (2009). Mediatization: A Concept With Which to Grasp Media and Societal Change. In K. Lundby (Ed.), Mediatization: Concept, Changes, Consequences (pp. 21-40). Peter Lang.

Laurie, J., \& Blandford, A. (2016). Making time for mindfulness. International Journal of Medical Informatics, 96, 38-50. https://doi.org/10.1016/j.ijmedinf.2016.02.010

Lilja, M., \& Vinthagen, S. (2014). Sovereign power, disciplinary power and biopower: Resisting what power with what resistance? Journal of Political Power, 7(1), 107-126. https://doi. org/10.1080/2158379X.2014.889403

Loder, V. (2015, March 18). How To Rewire Your Brain For Happiness. Forbes.com. https://www.forbes.com/sites/vanessalod er/2015/03/18/how-to-rewire-your-brain-for-happiness/\#8fb25 3259ef3. Accessed 01 July 2021.

Medlock, K. (2017, October 1). 6 things you need to know about job burnout. The Headspace blog. https://www.headspace.com/ blog/2017/01/10/job-burnout/. Accessed 02 July 2021.

Monteiro, L. M., Musten, R. F., \& Compson, J. (2015). Traditional and Contemporary Mindfulness: Finding the Middle Path in the Tangle of Concerns. Mindfulness, 6(1), 1-13. https://doi.org/10. 1007/s12671-014-0301-7

Pajer, N. (2016, September 12). 6 ways to stop guilt- tripping yourself. The Headspace blog. https://www.headspace.com/blog/ 2016/09/12/6-ways-to-stop-guilt-tripping-yourself/. Accessed 02 July 2021.

Purser, R. E. (2018). Critical perspectives on corporate mindfulness. Journal of Management, Spirituality and Religion, 15(2), 105-108. https://doi.org/10.1080/14766086.2018.1438038 
Purser, R. E. (2019). McMindfulness: How Mindfulness Became the New Capitalist Spirituality. Repeater Books.

Purser, R. E., and Loy, D. (2013). Beyond McMindfulness. Huffpost. https://www.huffingtonpost.com/ron-purser/beyond-mcmindfuln ess_b_3519289.html. Accessed 01 July 2021.

Press. (n.d.). Calm.com. https://blog.calm.com/press. Accessed 02 July 2021

Quandt, K. R. (2018, January 2). Are you stuck with your personality, or can you change it?. The Headspace blog. https://www. headspace.com/blog/2018/01/02/stuck-personality/. Accessed 02 July 2021.

Rose, N. (2001). The Politics of Life Itself. Theory, Culture and Society, 18(6), 1-30. https://doi.org/10.1177/026327601220520 20

Rose, N. (2007). The Politics of Life Itself. Biomedicine, Power, and Subjectivity in the Twenty-First Century. Princeton: Princeton University Press.

Scientific Rigor. (n.d.). Headspace.com. https://www.headspace.com/ science. Accessed 02 July 2021.

Sloterdijk, P. (2013). You must change your life (W. Hoban, Trans.). Cambridge: Polity.

Strauss, C., Dunkeld, C., \& Cavanagh, K. (2021). Is clinician-supported use of a mindfulness smartphone app a feasible treatment for depression? A Mixed-Methods Feasibility Study. Internet
Interventions, 25, 100413. https://doi.org/10.1016/j.invent.2021. 100413

Widdicombe, L. (2015, July 6). The Higher Life. A mindfulness guru for the tech set. The New Yorker. https://www.newyorker.com/ magazine/2015/07/06/the-higher-life. Accessed 02 July 2021.

Willard, C. (2016, May 2). A Basic Meditation to Strengthen Neural Connections. Mindful.org. https://www.mindful.org/a-basic-mindf ulness-practice-to-strengthen-neural-connections/. Accessed 02 July 2021.

Williams, J. M. G., \& Kabat-Zinn, J. (2011). Mindfulness: Diverse Perspectives on Its Meaning, Origins, and Multiple Applications at the Intersection of Science and Dharma. Contemporary Buddhism, 12(1), 1-18. https://doi.org/10.1080/14639947.2011.564811

Wilson, J. (2014). Mindful America: The Mutual Transformation of Buddhist Meditation and American Culture. Oxford University Press.

Yu, C. (2017, August 14). The science of being touched. The Headspace blog. https://www.headspace.com/blog/2017/08/14/scien ce-of-being-touched/. Accessed 02 July 2021.

Publisher's Note Springer Nature remains neutral with regard to jurisdictional claims in published maps and institutional affiliations. 